\section{Deatl Rates in the Registration Area}

To the Editor:-I notice in an editorial of THE Journal, Jan. 8,1915 , p. 118, a quotation of the reduction in the tuberculosis rate in the registration area. I have recently written an article on tuberculosis in which, among other things, I draw attention to the fact that this quotation of a reduction of death rate in the registration district is misleading.

Constantly the point is made that the death rate in the registration area at present is very different from that which existed in 1880, and apparently those who quote these facts assume that this reduction in rate is due to a diminished number of deaths from disease.

Such a statement would be true if the registration area of today were the same as that in 1880 . As a matter of fact, however, in 1880 there were only three divisions in the registration area, namely, Massachusetts, New Jersey and the District of Columbia. Every state which has been added to the registration area since 1880 has had a lower death rate at the time that it was added than existed in the three districts named. Hence, the very addition of these states would reduce the death rate in the registration area.

It is fair to quote the records of individual states to show the reduction in mortality rate from tuberculosis. It is misleading to quote the difference in the registration area as an evidence of reduction of mortality.

H. M. Bracken, M.D., St. Paul.

Executive Officer, Minnesota State Board of Health.

\section{Queries and Minor Notes}

Anonymous Communications and queries on postal cards will not be noticed. Every letter must contain the writer's name and address, but these will be omitted, on request.

\section{COAGULATION TIME OF BLOOD}

To the Editor:-1. What is the most efficient, practical and simple netliod of estimating the coagulation of the blood?

2. What is the technic of the drop-on-the-slide method? X. Y. Z.

ANSwER.-1. Coagulation time tests are described in all books on laboratory methods. Almost all the methods described require special apparatus, an exception being a method described in the book of Webster. This test is performed with a vacuum bottle and capillary tubes.

2. The drop-on-the-slide method consists of collecting drops of blood on a slide and then holding the slide, blood drops beneath, over a vessel containing water at body temperature. The slide is held in a vertical position from time to time; after coagulation has taken place the contour of the blood drop will not be changed by tilting the slide. Duke's method is like this, except that by using a slide with uniform sized disks on it, uniform sized drops of blood can be obtained. It has also been proposed, instead of observing the contour of the blood droplets, to dip the point of a fine capillary tube into them; as long as the blood is still fluid it will rise in the capillary tube.

\section{AMMONIUM HYDROGEN FLUORID}

To the Editor:-I would like some information regarding the therapeutic action of ammonium fluorid. The crystals of this compound are used in an aqueous solution for the removal of stains and calculi from the teeth. I would appreciate a formula for this use.

$$
\text { Roland B. Miller, D.M.D., Lebanon, Ore. }
$$

ANSwER.-There are two ammonium fluorids, normal or "neutral" ammonium fluorid $\left(\mathrm{NH}_{4} \mathrm{~F}\right)$ and acid ammonium fluorid, ammonium hydrogen fluorid or ammonium bifluorid $\left(\mathrm{NH}_{4} \mathrm{~F} . \mathrm{HF}\right)$, a combination of one molecule of ammonium fluorid and one molecule of hydrogen fluorid (hydrofluoric acid). The latter appears to be the salt used in dentistry. Ammonium hydrogen fluorid has been recommended for use as a solvent of tartar deposits on the dental enamel, and also as an amebicide in pyorrhea alveolaris; in the latter use it has been fargely supplanted by emetin hydrochlorid.

A formula said to be satisfactory is:

Ammonium hydrogen fluorid.......... $20 \mathrm{gm}$.

Hydrofluoric acid (40 per cent.).............. $10 \mathrm{gm}$

Water, enough to make............. 100 c.c.

The mixture should be kept in a wax or gutta-percha bottle.

\section{Medical Education and State Boards of Registration}

\section{COMING EXAMINATIONS}

Iowa: Des Moines, Feb. 8-10. Sec., Dr. G. H. Sumner, State House, Des Moines.

Kansas: Topeka, Feb. 8. Sec., Dr. H. A. Dykes, Lebanon.

New York: Albany, Buffalo, New York and Syracuse, Jan. 25-28. Chief, Examinations Division, Mr. Harlan H. Horner, State Education Bldg., Albany.

Vermont: Montpelier, Feb. 8-11. Sec., Dr. W. Scott Nay, Underhill.

\section{Washington July Report}

Dr. C. N. Suttner, secretary of the Washington State Board of Medical Examiners, reports the written examination held at Seattle, July, 6, 1915. The total number of subjects examined in was 11 ; total number of questions asked, 110; percentage required to pass, 75 . The total number of candidates examined was 64 , of whom 48 passed, including 8 osteopaths, and 16 failed, including 2 osteopaths and 2 chiropractors. The following colleges were represented:

College

PASSED

Year
Grad.

California Eclectic Medical College...............(1914)

College of Physicians and Surgeons, Los Angeles......(1914)

Gooper Medical College ......................... (1909)

Bennett Medical College...(1912) 78.8; (1913) 89.5 ; (1914) (1915) 85.3, 86.

Chicago College of Medicine and Surgery

Hahnemann Med. Coll. and Hosp., Chicago.(1895) 75; (1910) $\quad 89.5$

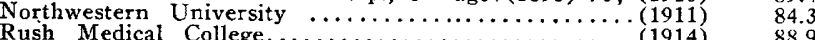

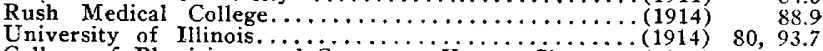

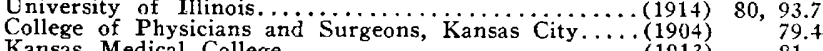

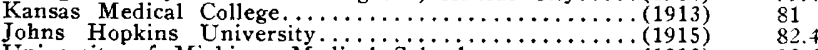

Johns Hopkins University.
University of Michigan Medical School................. (1915)

$\begin{array}{lll}\text { University of Michigan Homeo. Medical School....... (1913) } & 89 \\ \text { University of Minnesota....(1894) 75.5; (1914) } 81.2 ;(1915) & 89.6\end{array}$

University Medical College, Kansas City.............1903) 89.6

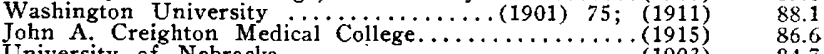

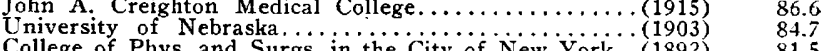

$\begin{array}{ll}\text { College of Phys. and Surgs. in the City of New York..(1892) } & 81.5 \\ \text { University and Bellevue Hospital Medical College...... (1899) } & 86\end{array}$

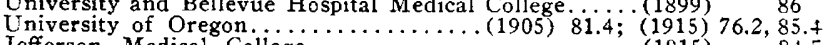

Jefferson Medical College......................(1915) 84.5

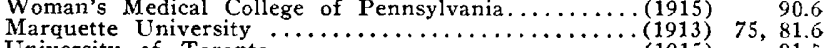

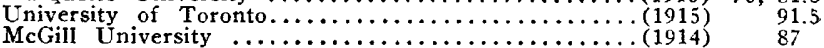

FAILED

College of Physicians and Surgeons, Chicago.........(1905)

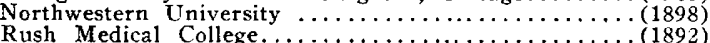

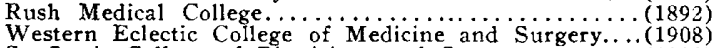

Western Eclectic College of Medicine and Surgery....(1908)

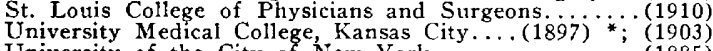

University of the City of New York................ (1885)

University of Pennsylvania ........................ (1910)

Nagasaki Special Medical School.................... (1905)

Okayama Special Medical School ...................(1907)

* No grade given.

$\dagger$ Fell below the required average in one or more subjects.

The following questions were asked:

TOXICOLOGY

1. In conducting postmortem examinations, outline your order of autopsy. 2. How would you determine sex between two adult skeletons of equal height? 3. Differentiate between antemortem and postmortern ecchymoses. 4. Differentiate postmortem appearance of death from hea stroke (insolation) and stroke by lightning. 5. In criminal abortion how would you determine same by the examination of the woman
(living)? 6. How would you in a railway injury differentiate between (living)? 6. How would you in a railway injury differentiate between from chronic phosphorus poisoning. 8. Potassium chlorate lethel dose (approximately); symptoms of, eliminated how? Postmortem findings? 9. Mention five vegetable poisons. 10. Differentiate opium from strych. nin poisoning. 11. What poisons are found in adulterated (commercialized) foods? 12. Give chemical test for arsenic.

\section{CHEMISTRY}

1. What are alkaloids? What are the general properties of the natural alkaloids? 2. Describe subnitrate of bismuth and explain the dark color of the stools resulting from its administration, 3. To what class of chemical substances does glycerin belong? 4. Define normal salt, acid salt, basic salt. What is a decinormal solution? Give example. 5. Carbon dioxid and carbon monoxid; give formula and general properties of each. 6. Give the chemical formula and general properties of plaster-of-Paris. Explain the process of "setting." 7. Give general properties and name antidote for phenol, construct its graphic formula and show its relation to benzene. 8 . Give in full one test for the presence of sugar in the urine. 9. How is ferric hydrate prepared, and for gallstones, and give in detail a reliable test for bile in the urine. 